\title{
Iron in Chronic Brain Disorders: Imaging and Neurotherapeutic Implications
}

\author{
James Stankiewicz,* S. Scott Panter, ${ }^{\dagger}$ Mohit Neema,* Ashish Arora,* Courtney E. Batt,* and \\ Rohit Bakshi** \\ Departments of *Neurology and ${ }^{\ddagger}$ Radiology, Brigham and Women’s Hospital, Harvard Medical School, Boston, Massachusetts \\ 02115; ${ }^{\dagger}$ Department of Neurological Surgery, Veteran's Administration Hospital, University of California, San Francisco, \\ California 94121
}

Summary: Iron is important for brain oxygen transport, elec-
tron transfer, neurotransmitter synthesis, and myelin produc-
tion. Though iron deposition has been observed in the brain
with normal aging, increased iron has also been shown in many
chronic neurological disorders including Alzheimer's disease,
Parkinson's disease, and multiple sclerosis. In vitro studies
have demonstrated that excessive iron can lead to free radical
production, which can promote neurotoxicity. However, the
link between observed iron deposition and pathological pro-

\section{INTRODUCTION}

Iron is vital for normal neuronal metabolism. Excessive iron, however, may be harmful. It has been demonstrated in vitro that free iron or iron overload can lead to free radical formation, lipid peroxidation, and neuronal damage. ${ }^{1}$ Iron accumulates as the brain ages and has been linked to motor and cognitive dysfunction in the elderly. ${ }^{2}$ Neuroferritinopathy, a genetic disorder of excessive brain iron storage, leads to cognitive and motor difficulties that resemble those seen in the elderly. ${ }^{3} \mathrm{~A}$ growing body of data suggests that brain iron accumulation in vivo may contribute to tissue damage in a variety of chronic neurological disorders. Histological and magnetic resonance imaging (MRI) data have suggested increases in iron levels in the gray matter in Parkinson's disease (PD), ${ }^{4-10}$ Alzheimer's disease (AD),${ }^{11-17}$ multiple sclerosis (MS) ${ }^{18-21}$ and a host of other chronic neurological disorders. ${ }^{22}$ Consequently, there is a growing interest in optimizing the ability of MRI to estimate iron

Address correspondence and reprint requests to: Rohit Bakshi, MD, Associate Professor of Neurology and Radiology, Brigham \& Women's Hospital, Harvard Medical School, 77 Avenue, Louis PasteurHIM 730, Boston, MA 02115. E-mail: rbakshi@bwh.harvard.edu. cesses underlying various diseases of the brain is not well understood. It is not known whether excessive in vivo iron directly contributes to tissue damage or is solely an epiphenomenon. In this article, we focus on the imaging of brain iron and the underlying physiology and metabolism relating to iron deposition. We conclude with a discussion of the potential implications of iron-related toxicity to neurotherapeutic development. Key Words: Iron, neurodegeneration, MRI, chelation, Alzheimer's disease, Parkinson's disease, multiple sclerosis. 


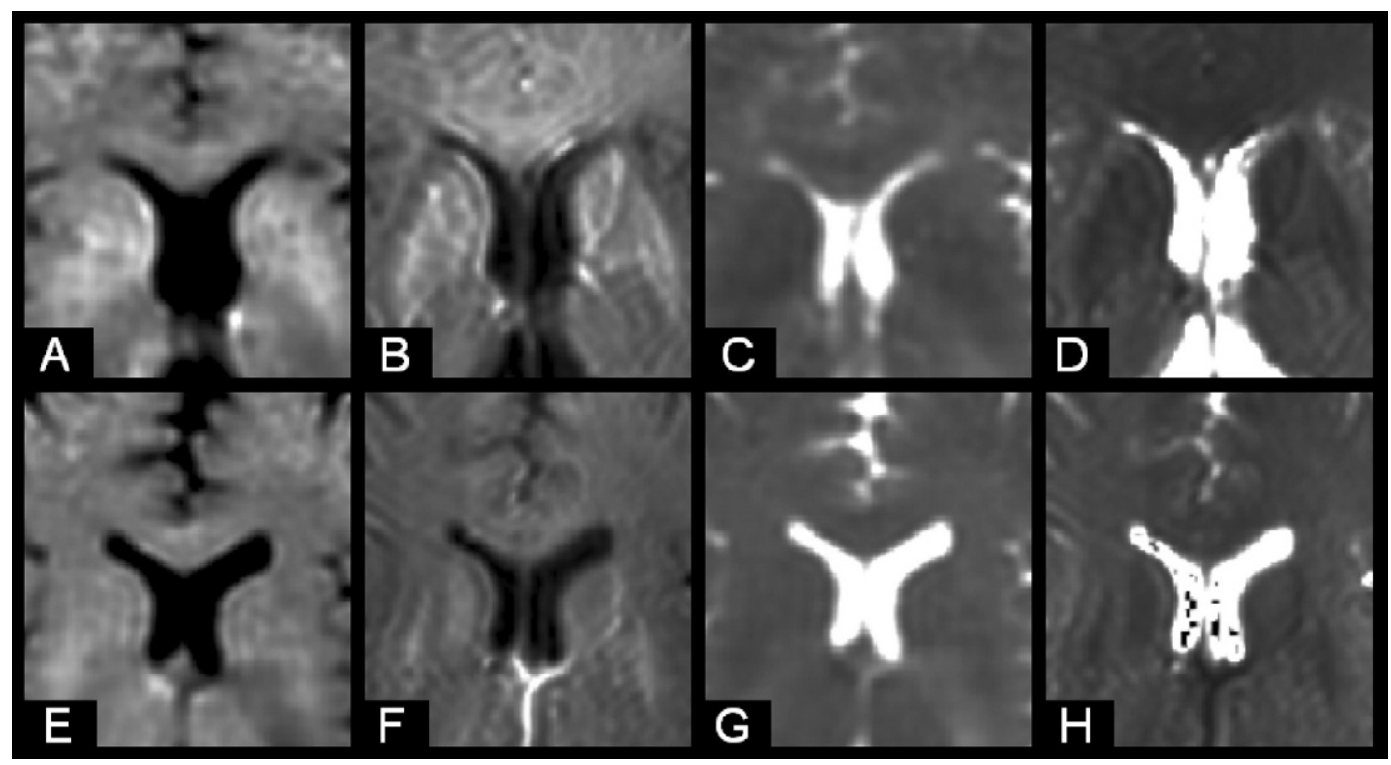

FIG. 1. T2 relaxometry at $3 T$ (axial images). Figures A-D are from a 47-year-old patient with relapsing remitting multiple sclerosis (MS) and $\mathbf{E}-\mathbf{H}$ are from a 47-year-old normal control. Figures $\mathbf{A}$ and $\mathbf{E}$ are R2 maps, $\mathbf{B}$ and $\mathbf{F}$ are R2* maps, $\mathbf{C}$ and $\mathbf{G}$ are T2 maps, and $\mathbf{D}$ and $\mathbf{H}$ are T2* maps. Note that hyperintensity in the caudate and putamen is prominent in the MS patient compared to the control subject on $\mathrm{R} 2$ and $\mathrm{R}^{*}$ maps because of increased relaxation rates. The T2 and T2* maps are effectively the inverse as they measure T2 and $\mathrm{T}^{*}$ relaxation times and are dark in the corresponding area in the MS patient relative to the control subject, due to shortening of relaxation times. The difference between the MS patient and control subject is more pronounced on the $\mathrm{R}^{*}$ and $\mathrm{T}^{*}$ maps compared to the R2 and T2 maps. Taken together, these findings are consistent with excessive striatal iron deposition in MS.

we will review the current status of the field of brain iron deposition with an emphasis on imaging, metabolism, histology, and pharmacological developments. We will review the detection of iron on conventional MRI studies and discuss new MRI techniques being developed to more sensitively and specifically quantify brain iron. We will review brain iron chemistry, iron trafficking, and how excessive iron may contribute to cellular damage and neurodegeneration. We will place these ideas into context with chronic neurological disorders associated with excessive brain iron deposition. We will conclude with a discussion of the current status of iron-related neurotherapeutics.

\section{MRI AND BRAIN IRON: TECHNICAL ASPECTS}

Magnetic resonance imaging has been proven to be important for in vivo characterization of iron deposition in aging and neurodegenerative disorders. When using MRI to detect brain iron deposition in chronic neurological disorders, ferritin and hemosiderin are considered to be the only forms of nonheme iron present in sufficient quantities to affect magnetic resonance contrast. ${ }^{26} \mathrm{Mag}$ netic resonance signaling is the result of mobile protons in tissue that lead to contrast with differences in the density of the solvent water in tissues reflected in two relaxation times of the protons: 1) longitudinal (T1) relaxation time and 2) transverse (T2) relaxation time. Contrast in MRI on T1 and T2 sequences in the brain is due to the interaction of water with protons and magnetic and paramagnetic ions. ${ }^{26}$ In general, magnetic and paramagnetic ions shorten the longitudinal and transverse relaxation times of the mobile protons in the brain. The end result is that areas with short $\mathrm{T} 1$ appear hyperintense on T1-weighted images, whereas areas with short T2 appear hypointense on T2-weighted images. A full discussion of the technical aspects of MRI-based iron assessment is beyond the scope of this review. The reader is referred to other excellent reviews. ${ }^{26-28}$

\section{Relaxometry}

Measurements of transverse and longitudinal proton relaxation rates in the brain from MRI can estimate brain iron concentrations. In an attempt to find answers to how iron and other tissue properties affect MRI, we will discuss the most relevant relaxometry metrics. The relaxation rates, $\mathrm{R} 2, \mathrm{R} 2 *$, and $\mathrm{R} 2$ ' are derived from $\mathrm{T} 2, \mathrm{~T} 2 *$, and T2' relaxation time decay curves. The rates, R2, $\mathrm{R} 2 *$, and $\mathrm{R} 2$ ' are the inverse of $\mathrm{T} 2, \mathrm{~T} 2 *$, and $\mathrm{T} 2$ ' and are increased by the presence of nonheme iron (FIG. 1). The rate, $\mathrm{R} 2 *$ is calculated from $\mathrm{T} 2 *$-weighted gradient echo sequences, whereas R2' is derived from the following equation: R2' = R2* - R2. The rate, R2' was developed to improve specificity for tissue iron by reducing the known R2 and R2* signal losses associated with local field inhomogeneity. ${ }^{27}$ Many in-vitro ${ }^{28,29}$ and invivo $^{30-38}$ studies have demonstrated a strong correlation between R2 and iron concentration as determined by histological studies of brain gray matter. A weaker cor- 
relation is obtained for white matter iron. This is most likely due to the influence of tissue water on R2. ${ }^{29,39}$ The effect of water content on R2 hampers the ability to estimate iron concentration in neurological diseases associated with a variety of pathological processes that increase water content (i.e., inflammation, gliosis, edema, and axonal/neuronal loss). Ordidge et al. ${ }^{40} \mathrm{dem}$ onstrated that R2' was significantly increased in the substantia nigra of patients with PD relative to controls, whereas R2 was not. The R2' increase better reflects histological data that consistently demonstrates excessive iron deposition in the substantia nigra in PD. Other groups $^{33,38,41}$ have also shown that R2' estimates iron concentration more accurately than R2. Many other researchers ${ }^{36,42,43}$ demonstrated that both R2 and R2' are affected by iron. Studies on R2* have reported limitations attributed to local background sources of magnetic field variation that reduce the specificity for iron. ${ }^{44}$ So in essence, R2 can be rendered somewhat insensitive by the water content in the brain, whereas $\mathrm{R} 2 *$ is susceptible to contributors other than iron, and R2' may have limited sensitivity. Sequences such as the gradient echo sampling of free induction decay and echo (GESFIDE) $)^{45-47}$ and partially refocused interleaved multiple echo (PRIME) $^{38}$ allow the derivation of R2, R2*, and R2' from a single-pulse sequence. The GESFIDE sequence consists of two echo trains, the first after an excitation pulse, the second after a 180-degree refocusing pulse. Hikita et al. ${ }^{47}$ studied various MRI sequences to see which of the metrics most accurately reflected brain iron, and they concluded that R2 obtained by GESFIDE sequence and $\mathrm{R} 2$ obtained by multiple spin echoes fitted to a single relaxation curve showed higher correlations with brain iron than R2' obtained by GESFIDE sequences. Yablonskiy et al..$^{48}$ has proposed a variation on the GESFIDE sequence called gradient echo sampling of the spin echo that samples only the rephasing and dephasing spin echo signal components, which they purport to have a lower signal-to-noise ratio compared to GESFIDE. The PRIME sequence comprises one spin echo and five gradient recalled echoes acquired with each $180^{\circ}$ radiofrequency pulse. Despite all of the previously mentioned advances, there is no single relaxometric measure that can be universally said to reliably quantify iron in the brain. This has driven the continuing development of techniques to better quantify in vivo iron concentration.

A newer relaxometry measure, T2 rho, has been developed, which is more sensitive to diffusion and exchange of water protons in environments with different local magnetic susceptibilities. Shortening of $\mathrm{T} 2$ rho likely reflects tissue iron concentration better than conventional MRI. Rather than a standard acquisition without radiofrequency irradiation, $\mathrm{H}_{2} \mathrm{O}$ MR signal is acquired in the presence of a radiofrequency pulse. Wheaton et al. ${ }^{49}$ demonstrated an increase in iron-related contrast when comparing images created with $\mathrm{T} 2$ rho to conventional $\mathrm{T} 2$ in the normal human brain. Using a $4 \mathrm{~T}$ magnet with a rotating frame and applying adiabatic pulses, Michaeli et al. ${ }^{50}$ demonstrated a statistically significant shortening of relaxation times in substantia nigra tissue in patients with PD compared to normal controls with T2 rho but not with routine T2. This correlates with postmortem observations of excessive iron deposition associated with the disease and suggests that this novel technique generates better iron-related contrast than conventional T2 methodology.

\section{Field dependent rate increase}

Field-dependent rate increase is a technique studied extensively by Bartzokis et al. ${ }^{43}$ using differing MRI field strengths (e.g., 1.5 and 3T) to compare T2 relaxation times in the same tissue area. Increasing R2 values with higher field strength are directly proportional to ferritin concentration, as shown by correlations with published brain iron concentrations and iron levels in phantom solutions.

\section{Magnetic field correlation}

Jensen et al., ${ }^{51}$ have developed a new technique referred to as magnetic field correlation (MFC), which uses asymmetric spin echoes to quantify brain iron. Magnetic field correlation is based on the influence of magnetic resonance signaling by magnetic field inhomogeneities (due to spatial variations in magnetic susceptibility). These changes can be due to macroscopic structures such as cavities, bones and vessels, microscopic structures such as capillaries, and the presence of paramagnetic substances (e.g., metals, contrast agents). Magnetic field correlation imaging is based on a theoretical model of magnetic resonance relaxation in the presence of magnetic field inhomogeneities and uses a nonmonoexponential decay curve. Jensen et al. ${ }^{51}$ reported that MFC maps showed more contrast between the basal ganglia and adjacent tissue than corresponding R2 maps. This led the investigators to conclude that MFC imaging can provide a more sensitive method for quantifying brain iron than R2, although there was no comparison made with $\mathrm{R} 2 *$ or R2'. Because MFC grows with the square of applied field strength, it was suggested that high field scanners (e.g., 3T or greater) are most suitable for MFC imaging. Because MFC is affected by water diffusion, nonuniform diffusion, as seen in edematous tissues, may introduce error. It should also be noted that MFC measures magnetic field inhomogeneities, which may be due to any type of magnetic substance, such as other transitional metals found in tissue. 


\section{BIOCHEMISTRY AND PHYSIOLOGY OF BRAIN IRON}

Iron plays an important role in the maintenance of many neurobiological processes. It is essential for the transport of oxygen, electron transfer, synthesis of neurotransmitters and production of myelin. ${ }^{52,53}$ In addition, normal aging is characterized by increasing brain iron accumulation. The physiological, biochemical, and anatomical aspects of iron homeostasis are important to understand in healthy individuals to lay a foundation for understanding the role of iron in chronic neurological disorders.

\section{Iron transport}

The pathway that dietary iron takes to get to the brain begins in the intestines where $\mathrm{Fe}^{3+}$ (ferric iron) is reduced by duodenal cytochrome $\mathrm{b}$ to $\mathrm{Fe}^{2+}$ (ferrous iron). In this reduced form, the divalent metal transporter can carry iron across the duodenal epithelium into the blood. Multiple proteins regulate gut intake to help achieve homeostasis. In the blood, $\mathrm{Fe}^{2+}$ is oxidized to $\mathrm{Fe}^{3+}$ by ceruloplasmin or hephaestin so that it can be coupled with transferrin, which is the predominant serum iron carrier protein. ${ }^{52,54,55}$

However, iron circulating in this form in the blood outside of the CNS can not directly cross the blood brain barrier (BBB). There are several pathways that can transfer iron across the BBB. The first and probably most common pathway is through transferrin receptors on brain endothelial cells that bind iron circulating in the form of transferrin. The transferrin receptor-bound complex then enters the brain by endocytosis. Several other transporter systems may also deliver iron across the $\mathrm{BBB}$, such as the divalent metal transporter and the lactoferrin receptor. ${ }^{52,56}$

In addition, these pathways, especially the transferrinreceptor mediated pathway, are the main avenues for iron transport within the CNS (i.e., into various cell types of the brain). The amount of iron taken up and stored by the cells is a function of the abundance of the transferrin receptor and its ligand. ${ }^{56}$ This can be controlled at the post-transcriptional level by iron regulatory proteins that interact with iron responsive elements on RNA to alter the expression of ferritin and the transferrin receptors on brain endothelial cells, neurons, glia, and oligodendrocytes. ${ }^{55,56}$ When there is not enough iron in the milieu, iron regulatory proteins bind to iron responsive elements to increase the stability of the transferrin receptor and decrease the expression of ferritin. This essentially allows the cell to uptake more iron and use it efficiently without it first being bound to the storage protein, ferritin. ${ }^{55}$ Ferritin is the most common iron-storage protein in the brain. It consists of two types of subunits, the heavy and light chains that work in complementary ways to store intracellular iron. Heavy ferritin efficiently se- questers iron and is found in organs with high-iron utilization and little iron storage, whereas light ferritin is associated with iron storage. ${ }^{57,58}$ Another sequestrant of iron found in high concentrations in the substantia nigra and locus ceruleus is neuromelanin. There is evidence to suggest that neuromelanin acts to reduce potentially toxic iron by chelating iron found in the cytosol of neurons. ${ }^{59,60}$ The CSF and brain interstitium probably also contain unbound extracellular iron, which is likely complexed with citrate and taken into cells through a nontransferrin receptor-mediated mechanism. ${ }^{61}$ Finally, after the brain uses the iron it has stored, the iron must leave the cell, and the copper-associated protein ceruloplasmin may facilitate cellular release of iron. ${ }^{52,54}$ Iron leaves the body via bleeding or through the shedding of skin and other cells. $^{55}$

\section{Iron toxicity}

In vitro iron accumulation has been shown to lead to cell damage. Ferritin-bound iron is considered "safe" because the iron therein does not react with surrounding molecules in a detrimental way. But a breakdown of the protective ferritin molecule or an overload of free iron due to a lack of ferritin in cells is highly toxic. ${ }^{1,62}$ The release of free iron in the brain can result from the breakdown of heme by heme oxygenase-1, which can initiate oxidative stress. ${ }^{63}$ Free iron (unlike soluble stable ferritin) when converted into hemosiderin and other oxyhydroxide derivatives becomes more likely to exchange electrons with surrounding molecules. These hemosiderin and oxyhydroxide compounds may initiate and propagate the production of free radicals, leading to lipid peroxidation. ${ }^{1}$ Neurotoxicity may result from a biochemical reaction involving the production of a reactive oxygen species through iron-induced oxidation of hydrogen peroxide. Specifically, via the Fenton reaction, ${ }^{64} \mathrm{Fe}^{2+}$ donates an electron to hydrogen peroxide. The resulting products are $\mathrm{Fe}^{3+}, \mathrm{OH}^{-}$, and the free radical $\mathrm{OH}^{64}$ Polyunsaturated fats in the brain, such as in cell membranes can then donate an electron to this highly reactive free radical. The products of this reaction, organic free radicals, can interact with oxygen to create oxygen radicals that can continue the cycle of making organic free radicals, creating a self-perpetuating "viscous cycle." Once the reactive oxygen species are generated, these species can participate in the oxidative destruction of the lipids, which are important parts of the cytostructure, such as cell membranes. ${ }^{1}$ This destructive pathway is continuously propagated by the excess of reactive iron and is a potential cause of cellular apoptosis. Thus, this hypothesis contends that iron deposition results in tissue damage by either directly damaging cells or changing the cellular environment so that it is more susceptible to toxins or other pathological processes. 


\section{Endogenous protection from iron-related damage}

In the brain, several endogenous antioxidants and enzymes are responsible for alleviating the deleterious effects of reactive oxygen species and free radicals that are created in normal metabolic processes. One antioxidant system in the brain involves glutathione. In this system, glutathione in a reduced state interacts with hydrogen peroxide and other organic peroxides to yield an oxidized form of glutathione, water, and alcohol. This reaction removes the likelihood of a reaction between the peroxides and iron that creates reactive radical species. ${ }^{65}$ Glutathione has been shown to protect murine astrocyte cultures from iron-induced neurotoxicity. This reaction is catalyzed by the enzyme glutathione peroxidase and is accomplished by the clearance of hydrogen peroxide. ${ }^{65}$ Experimental work has also demonstrated cells that are able to survive iron-induced toxicity do so by increasing the intracellular level of glutathione ${ }^{66} \mathrm{~A}$ form of vitamin E (i.e., alpha tocopherol) also plays a role as an antioxidant in limiting lipid peroxidation by donating a proton to reactive oxygen species, thus making them more stable and less reactive. ${ }^{67}$ When the alpha tocopherol analogue, 2,3-dihydro-2,2,4,6,7-pentamethyl-3-[(4-methylpiperazino)-methyl]-1-denzofuran-5-ol dihydrochloride (MDL 74,180) was added to cerebellar granule cell cultures before treatment with iron, brain injury, and cell toxicity were attenuated. ${ }^{68}$ Similarly, even transient alpha tocopherol administration to hippocampal neurons results in decreased iron-induced oxidative damage. ${ }^{69}$

\section{Histology, topography, and in vivo characterization of brain iron with aging}

Microscopic iron distribution. It is important to understand the normal cellular and anatomic age-dependent distribution of iron so that differences may be appreciated when considering abnormal iron deposition. ${ }^{70} \mathrm{Im}$ munohistochemical iron staining reveals that iron, ferritin, and transferrin are found in various cell types and in widespread brain regions. Strong staining for iron, ferritin, and transferrin indicates that oligodendrocytes are the primary repository for iron in the brain. ${ }^{71}$ Microglia in the cerebral cortex and astrocytes in the basal ganglia also stain positive for ferritin. Neurons inconsistently stain for transferrin, whereas neuronal iron is present predominantly in the form of neuromelanin. ${ }^{59,72}$ In microglia and astrocytes, an increase in iron staining correlates positively with the age of the subject. Conversely, oligodendrocytes do not show an increase in staining iron with age..$^{71,73}$ In neurons, it is believed that the iron-ferritin complex is assembled in the cell body and then transported along axons. Presumably axonal disruption as a result of disease processes or normal aging could disrupt this transport. This could be one way that a neuropathological process leads to iron accumulation. In the absence of injury, ferritin that reaches its target area is then degraded by lysosomes so that the iron can be used. $^{74}$

Macroscopic iron distribution. Using conventional MRI, iron deposition in the brain has been observed to appear in the globus pallidus as early as 6 months after birth. ${ }^{75}$ The same study showed evidence of iron deposition in the substantia nigra at 9 to 12 months, the red nucleus at 18 to 24 months, and the dentate nucleus at 3 to 7 years of age. In a landmark postmortem study of 81 normal brains, Hallgren and Sourander ${ }^{76}$ showed a progressive increase in whole brain iron deposition until the end of the third decade of life. Levels then stabilized until approximately the sixth decade of life and then slowly increased. Thomas et al. ${ }^{77}$ added that during the first three decades the substantia nigra exhibits the most profound $\mathrm{T} 2$ hypointensity. Using conventional MRI, Milton et al. ${ }^{78}$ noted a relative paucity of iron deposition in the thalamus and caudate with aging and added that iron deposition occurs significantly in the putamen only in those aged 60 or greater. The locus ceruleus accumulates iron more slowly than the substantia nigra. ${ }^{73}$ With increasing age, iron increases in astrocytes and microglia, although the primary cellular repository for iron (i.e., the oligodendrocyte) undergoes little accumulation. $^{72,74}$ Bartzokis ${ }^{79,80}$ has demonstrated by MRI that women have significantly lower ferritin iron in areas such as the caudate, thalamus, and white matter than men. The group speculates that the slower increase of iron in the female brain may to a certain extent explain why women tend to develop $\mathrm{AD}$ and $\mathrm{PD}$ at a more advanced age then men. Interestingly, in rhesus monkeys, increases in MRI-based brain iron content were strongly correlated with age-related motor dysfunction. ${ }^{81}$ There is a suggestion that this result may extend to humans; even in "healthy" adults, decreased signal T2 intensities were correlated with deficits in motor and cognitive tasks. ${ }^{2}$

\section{IRON DEPOSITION IN CHRONIC BRAIN DISORDERS}

Views concerning the role of iron deposition in the CNS have undergone considerable advances during the last decade. It has now become clear that iron deposition occurs in the adult brain in a variety of chronic neurological disorders such as AD and PD, and probably also MS. ${ }^{22,74}$ However, it is still unclear whether the increased iron content is purely an epiphenomenon or actually contributes to tissue damage in these disorders. In this section, we provide an overview of histological, experimental, and MRI findings that help to shed light on the role of brain iron in a variety of neurological disorders. 


\section{Alzheimer's disease}

Iron deposition is gaining increased recognition as a putative factor in the pathogenesis of AD. Animal models, pathological studies, and MRI have linked iron to AD. Animal studies suggest that excessive iron contributes to oxidative stress and neuronal injury through the production of hydroxyl free radicals. ${ }^{74,82}$ Animal models also suggest that increases in iron may either worsen the course or increase the risk of developing AD. It is also established from postmortem pathology studies that iron deposition occurs in neurons, neurofibrillary tangles, and plaques of patients with $\mathrm{AD} .{ }^{17}$ Progress has been made in identifying the role of iron in $\mathrm{AD}$ using experimental in vivo and in vitro models. For example, iron exacerbates amyloid-induced neuronal injury in human neuroblastoma cell line $\mathrm{M} 17^{83}$ and also enhances aggregation of beta amyloid proteins in vitro. ${ }^{84}$ Bishop and Robinson $^{85}$ used an in vivo rat model of $\mathrm{AD}$ to show that iron augments beta amyloid neurotoxicity. Furthermore, genetics studies have also indicated that mutations of genes involved in iron management can increase the risk of AD. Mutations in the transferrin ${ }^{86}$ and hereditary hemochromatosis gene ${ }^{87}$ lead to deranged iron metabolism and confer a risk for development of AD.

Investigators have used MRI to detect increased brain iron content in vivo in patients with $\mathrm{AD}$. Using the fielddependent rate increase, Bartzokis et al. ${ }^{30,32,88}$ demonstrated increased iron levels in the caudate and putamen in patients with $\mathrm{AD}$ compared to normal controls. Interestingly, increased iron levels were found in patients with young onset $\mathrm{AD}$ compared with patients with older onset $\mathrm{AD},{ }^{88}$ which supports the notion that high-brain ferritin may be a risk factor for early age of $\mathrm{AD}$ onset. ${ }^{89}$ A study by House et al. ${ }^{90}$ measured R2 in 14 brain regions in patients suffering from memory dysfunction and showed increased iron in the temporal gray matter (most notably the hippocampus) when compared to normal controls. In these cohorts, no difference in white matter iron was found. ${ }^{90}$ In a separate study using highresolution 4.7T MRI, this same group of investigators showed a direct correlation between $\mathrm{R} 2$ and iron concentrations in postmortem brain tissue obtained from patients with AD. ${ }^{11}$ The study also corroborates previous studies demonstrating increased basal ganglia iron levels in patients with $\mathrm{AD} .^{30,32}$ Collectively these studies suggest that brain gray matter iron deposition may facilitate some of the early neurodegenerative changes seen in AD. It is now evident that excessive brain iron deposition occurs in AD. Further investigations need to be performed to better establish the link between iron-mediated toxicity and $\mathrm{AD}$ pathogenesis to ultimately determine if this link provides new therapeutic targets. Inhibition of beta-amyloid production in $\mathrm{AD}$ patients would likely either slow or halt disease progression. Decreased iron, copper, and zinc-mediated damage may disrupt beta amyloid production and its potential toxic effects. It has been demonstrated in vitro that neurons pretreated with desferrioxamine (DES), an iron chelator, then exposed to beta-amyloid experience less toxicity than neurons not pretreated with DES. ${ }^{83}$ Small clinical studies of both DES and another iron-related therapy have been conducted in AD. In the DES trial, 48 patients with probable $\mathrm{AD}$ were randomly assigned to receive DES (125 mg intramuscularly twice daily, 5 days per week for 24 months), oral placebo (lecithin), or no treatment. The DES treatment led to significant reduction in the rate of decline of daily living skills as assessed by both group means $(p=0.03) .^{24}$ It is interesting that this effect was achieved despite DES's inability to cross the BBB. It is speculated that the BBB may be damaged in AD, allowing for the observed treatment effect. The chelator clioquinol is thought to act not only on iron but to inhibit zinc and copper ions from binding to beta amyloid. In a mouse model of $\mathrm{AD}$, clioquinol decreased brain beta amyloid deposition. ${ }^{91}$ Based on the strength of the data, a pilot study of clioquinol in patients with $\mathrm{AD}$ was performed. ${ }^{23}$ The AD patients $(n=18)$ who received clioquinol showed a decrease in plasma beta amyloid levels when compared with 18 patients receiving placebo. After 36 weeks of treatment there was a trend toward improved cognition in the clioquinol group that approached statistical significance $(p<0.07)$. Although the drug was well tolerated in this study, the manufacturer recently stopped making clioquinol because of difficulties with the manufacturing process.

\section{Parkinson's disease}

Many, but not all ${ }^{92,93}$ studies have reported excessive iron deposition in the substantia nigra of patients with PD. Years of research using postmortem and in vivo MRI, histochemical methods, and transcranial ultrasound have yielded many advances in heightening the awareness of iron deposition in PD. Quantitative studies have shown a $25 \%$ to $100 \%$ increase in substantia nigra iron levels in patients with PD compared to normal controls. ${ }^{6}$ Additionally, iron-associated proteins and receptors are upregulated in the striatum and substantia nigra of patients with PD. ${ }^{60,94}$ Increased iron levels are thought to produce free radicals and predispose dopamine striatonigral neurons to oxidative damage. ${ }^{60,94-96}$ Oxidative stress compromises lipid, protein, and DNA molecular integrity, leading to neuronal injury. Dexter et al. ${ }^{97}$ were unable to demonstrate a significant increase in iron levels in the intracellular Lewy body found in the substantia nigra. There is controversy whether or not Lewy bodies have increased iron (FIG. 2). Using in vivo transcranial sonography, Zecca et al. ${ }^{98}$ recently showed increased iron levels in subjects with Lewy bodies and suggested that iron may be involved in initiating and promoting the neurodegenerative cascade in PD. Although there is ev- 


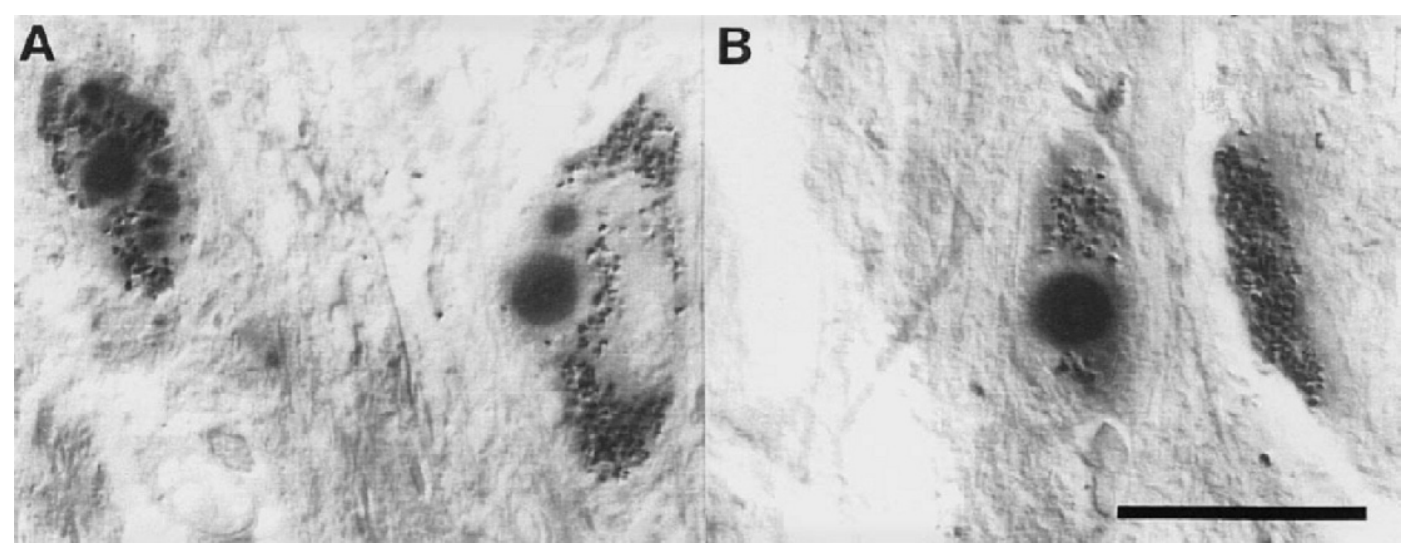

FIG. 2. Viable pigmented neurons of the substantia nigra pars compacta in two separate cases (A and B) of Parkinson's disease show strong iron (II or III) labeling of the Lewy bodies. The most pronounced staining involves the Lewy body core. Iron labeling of neuromelanin granules is also present, as expected. Reproduced with permission from Castellani RJ, Siedlak SL, Perry G, Smith MA. Acta Neuropathol 2000;100:111-114.

idence that increased iron has a role in the pathogenesis of $\mathrm{PD}$, it remains possible that iron is simply an epiphenomenon.

Magnetic resonance imaging has emerged as a powerful tool in detecting abnormal brain iron deposition in vivo in patients with PD. Patients with PD may show T2 hypointensity in many anatomic areas compared to normal controls, including the substantia nigra pars compacta, dentate nucleus, subthalamic nucleus, and basal ganglia, probably reflecting excessive iron content. ${ }^{22}$ Using the field-dependent rate increase method, Bartzokis et al. ${ }^{31}$ showed increased basal ganglia iron deposition in patients with young onset PD compared to normal controls. In a study involving 20 patients with PD, Atasoy et al. ${ }^{99}$ demonstrated a correlation between $\mathrm{T} 2$ hypointensity of the substantia nigra pars compacta and clinical severity. In a study of 13 patients with PD, using 3T MRI and iron relaxometry techniques, Gorell et al. ${ }^{41}$ demonstrated elevated iron levels in the substantia nigra compared to normal controls. There was also a strong association between iron concentration and motor performance. ${ }^{41}$ Using the partially refocused interleaved multiple echo MRI sequence, Graham et al. ${ }^{38}$ showed an increase in $\mathrm{R} 2$ ' and $\mathrm{R} 2 *$ in the substantia nigra of PD patients when compared with normal controls. However, R2' and R2* did not correlate with clinical impairment. In another study, using the T2 rho MRI method, Michaeli et al. ${ }^{50}$ showed increased substantia nigra iron levels in patients with PD versus normal controls. Kosta et al. ${ }^{100}$ compared T2 intensity in the substantia nigra pars compacta and subthalamic nucleus in 40 patients with PD and 40 normal controls. The authors demonstrated that patients with PD had significantly lower T2 intensity in the substantia nigra pars compacta and subthalamic nucleus. The degree of T2 hypointensity in the subthalamic nucleus was correlated with the disease duration.

Although no human trials have been completed to date, a variety of iron chelators have been used in rat and mouse models of PD. Animals induced with a PD-like illness developed heavy iron loads in the substantia nigra pars compacta, which is anatomically analogous to the iron deposition that has been demonstrated in human PD. ${ }^{101}$ Interestingly, a nutritional reduction of iron in a kainate rat model has shown reduced cellular damage in piriform and entorhinal cortex, thalamus, and in hippocampal layers CA1-3. ${ }^{102}$ There was also attenuated gliosis when compared to controls. The iron chelator, DES, has been studied extensively in animal models of PD. Despite some concern about use in humans due to an unfavorable side effect profile, it has been successful in rat 6-hydroxydopamine, and 1-methyl-4-phenyl-1,2,3,6tetrahydropyridine (MPTP)-induced PD models. DES, when injected periventricularly before the administration of 6-hydroxydopamine, resulted in significant protection of striatal dopamine and a normalization of behaviors that were impaired in the rat control group. ${ }^{103} \mathrm{~A}$ similar effect was shown in the MPTP model. ${ }^{104}$ Clioquinolpretreated MPTP mice had total substantia nigra iron levels decreased 30\% when compared to control animals. ${ }^{105}$ The iron levels obtained after clioquinol pretreatment were below known toxic levels. ${ }^{105}$

\section{Multiple sclerosis}

There is growing interest regarding the significance and impact of iron in the pathophysiology of MS. It has generally been found that patients with MS often show T2 hypointensity or other MRI changes suggestive of iron deposition in gray matter areas, including the red nucleus, thalamus, dentate nucleus, lentiform nucleus, caudate, and rolandic cortex compared to age-matched normal controls (FIGS. 1 and 3). ${ }^{18,19,21,106-108}$ Supporting evidence for the role of iron in MS comes from studies involving postmortem human brain histology, in vivo human MRI, and experimental autoimmune enceph- 


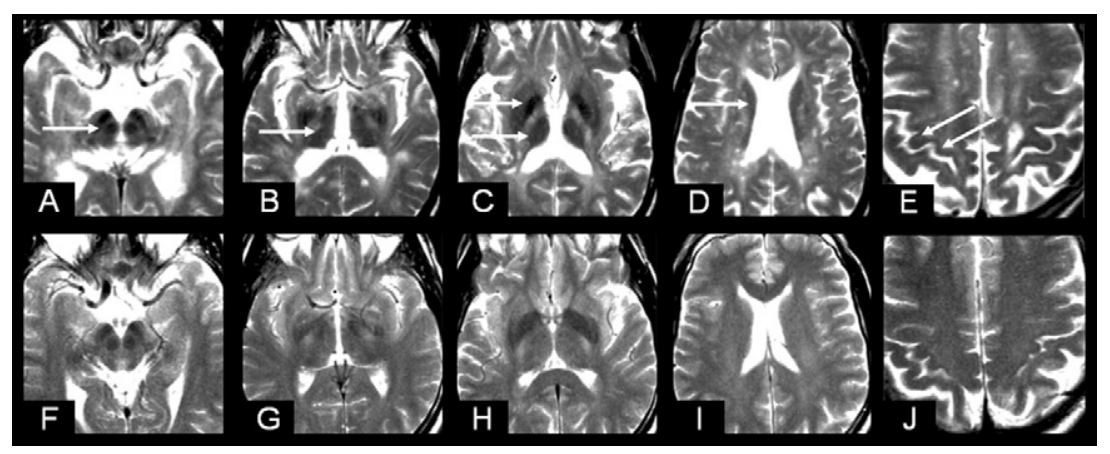

FIG. 3. Gray matter T2 hypointensity and brain atrophy in multiple sclerosis (MS). Fast spin-echo axial T2-weighted images of a 43-year-old man with relapsing-remitting MS (disease duration of 4 years with mild-to-moderate physical disability; Expanded Disability Status Scale score 3.5; images A-E) and an age-matched healthy subject (images F-J). In the patient with MS, note the bilateral hypointensity of various gray matter areas (arrows), including the red nucleus (A), thalamus (B, C), lentiform nucleus (B, C), caudate (D), and rolandic cortex (E) compared to the healthy subject. The patient also has brain volume loss compared to the control; note prominence of ventricular and subarachnoid spaces. The T2 hypointensity most likely represents pathological iron deposition. Reprinted with permission from Pirko I, Lucchinetti CF, Sriram S, Bakshi R. Neurology 2007;68:634-642.

alomyelitis (EAE), an animal model of MS. In an autopsy-based study, Craelius et al. ${ }^{20}$ found abnormal brain iron deposits in the neurons and oligodendrocyte of five patients with MS. Drayer and colleagues ${ }^{18}$ demonstrated increased ferric iron content in the putamen and thalamus in an MS brain at autopsy. LeVine ${ }^{109}$ showed iron deposits in macrophages and microglia in postmortem MS brain tissue. Mehindate et al. ${ }^{110}$ showed upregulation of heme oxygenase-1 (i.e., a stress protein that helps regulate iron metabolism) in MS spinal cord astrocytes, and they suggested that iron metabolism is deranged in patients with MS. Chakrabarty et al. ${ }^{111}$ demonstrated that the motor deficits seen in mice suffering from EAE can be improved by suppression of heme oxygenase activity. Iron deposits have also been found intracellularly (inside macrophages and astrocytes) and in extracellular CNS areas in EAE mice compared to control mice. ${ }^{112}$

Whereas laboratory-based studies suggest a role for iron in MS, MRI-based human studies suggest a link between iron deposition, gray matter damage, and clinical status. Gray matter T2 hypointensity can be detected in patients with MS (FIGS. 1 and 3), and with more severity in patients with secondary progressive than relapsing-remitting $\mathrm{MS}^{18,19,21,106-108,113,114}$ as compared to age-matched normal controls. In a study involving 68 patients with early relapsing-remitting MS, Bermel et al. ${ }^{115}$ demonstrated that baseline T2 hypointensity in the gray matter was the best predictor of whole brain atrophy compared to conventional MRI findings. These results in addition to cross-sectional analyses ${ }^{19}$ link T2 hypointensity to brain atrophy. Numerous studies have showed a link between $\mathrm{T} 2$ hypointensity in the gray matter and clinical manifestations of MS. Tjoa et al. ${ }^{107}$ showed a correlation between dentate nucleus $\mathrm{T} 2$ hypointensity and ambulatory function as measured by the timed 25foot walk $(r=-0.355 ; p=0.007)$ and physical disability score $(r=-0.463 ; p=0.004)$ in 47 patients with MS. ${ }^{107}$ Brass et al. ${ }^{114}$ demonstrated a correlation be- tween gray matter T2 hypointensity and cognitive impairment in patients with MS. In each of these studies, $\mathrm{T} 2$ hypointensity in the gray matter was more closely associated with neurological status than were conventional MRI lesion measures. Additional data supporting a role for excessive gray matter iron deposition in MS comes from recent work using advanced MRI techniques, such as T2 intensity measures with $3 \mathrm{~T}$ MRI ${ }^{116}$ and MFC. ${ }^{21}$ In addition, our group is in the process of measuring R2, R2*, and R2' with 3T MRI to assess potential brain iron deposition in patients with MS (FIG. 1).

There is a relatively small quantity of literature regarding the effect of iron chelation therapy in MS. Trials of DES and dexrazoxane (a chelator similar to DES) have been completed in animals. Rats with EAE treated with DES before symptom development experienced total symptom suppression, whereas rats treated after symptom manifestation had a rapid marked attenuation of symptoms. ${ }^{117} \mathrm{~A}$ study with a myelin basic protein-induced rat EAE model failed to show a treatment effect when DES was administered in the preclinical stage. ${ }^{118}$ Postulating that DES scavenges and prevents free radical formation, and consequently will only be efficacious during active disease, Pedchenko et al. ${ }^{119}$ treated rats in the active stage of EAE and observed significantly reduced clinical signs when compared to vehicle-treated animals. Dexrazoxane, when injected alone into rats, slightly attenuated the course of EAE, whereas rats given dexrazoxane concomitantly with mitoxantrone experienced improvement on clinical indices when compared with rats treated solely with mitoxantrone. ${ }^{120}$ This result is of special interest because mitoxantrone carries a significant risk of cardiotoxicity even though it is an effective FDA-approved MS therapy, whereas dexrazoxane is known to have cardioprotective effects. ${ }^{121}$ Only one human trial of iron-related therapy has been performed in human MS (DES in secondary progressive MS); after 2 
years there was no significant improvement in disability score following up to 8 courses of DES. ${ }^{25}$ This lack of treatment effect may potentially be attributed to the advanced disease in the patient population and the small number of the study participants $(n=9)$.

It is evident from the studies previously presented that iron deposition occurs in MS and that iron chelation is effective at ameliorating symptoms in animal models. It is unclear, however, the precise role that iron deposition plays in humans and whether chelation therapy or other therapies targeting iron-related toxicity can benefit MS patients. Additional studies are warranted to further define the role of iron deposition in MS.

\section{Other chronic brain disorders}

Brain iron deposition has been implicated as playing a role in other neurological diseases. A few of these disorders will be discussed briefly.

Neuroferritonopathy, a disorder characterized by extrapyramidal symptoms, is thought to be due to a mutation in ferritin light chain gene 1. Serum ferritin levels are typically low. Conversely, brain accumulation of ferritin and iron has been demonstrated. ${ }^{122}$ Iron accumulation likely directly causes clinical symptoms and neurodegeneration by free radical toxicity as previously discussed. Affected individuals have MRI evidence of iron deposition in the basal ganglia. As the disease progresses, T2* gradient echo MRI reveals worsening hypointensity in the dentate, thalamus, globus pallidus, lentiform, and caudate nuclei. ${ }^{123}$

Friedrich's ataxia (FA), an autosomal recessive disease that presents neurologically with progressive ataxia, areflexia, and sensory loss, is thought to originate from a deficiency of the mitochrondrial protein frataxin. Interestingly, elevated iron levels and oxidative damage have been observed in a yeast frataxin knockout model. ${ }^{124}$ Patients with abnormal FRDA, the gene that leads to frataxin expression, showed increased oxidative damage. This may accelerate disease progression. The MRI showed significantly increased iron concentration in the cerebellar dentate nucleus of patients with FA when compared with normal controls. ${ }^{125}$ Although no chelation trials have been performed in FA, there is evidence that the antioxidants coenzyme q10 and vitamin E may improve cardiac and skeletal muscle function. ${ }^{126} \mathrm{Re}-$ cently a novel iron chelator, 2-pyridylcarboxaldehyde isonicotinoyl hydrazone (PCIH), has been suggested as a potential therapeutic agent for FA. The PCIH is known to enter mitochondria and bind mitochondrial iron. Presumably, because a dearth of the mitochondrial protein frataxin leads to toxic mitochondrial iron accumulation, a compound such as PCIH may be able to attenuate mitochondrial damage and either slow or halt disease progression. However, PCIH has yet to be tested in clinical trials. $^{82}$

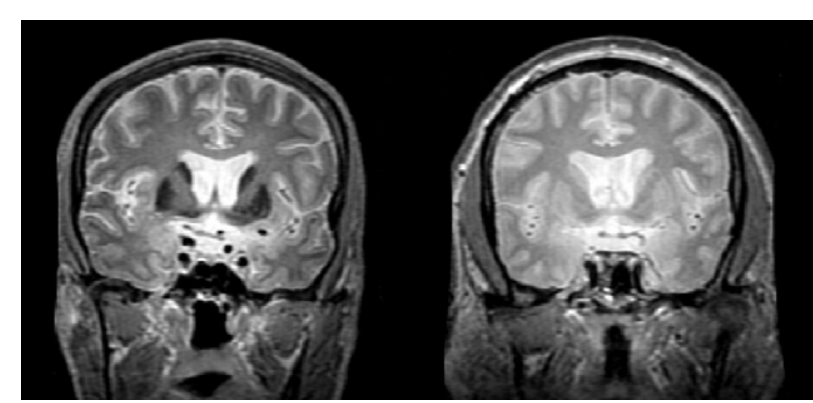

FIG. 4. The MRI findings in aceruloplasminemia. Axial T2weighted spin-echo MRI at 3T (2 mm slice thickness, field-ofview $22 \mathrm{~cm}$, TR $9000 \mathrm{~ms}$, echo time [TE] $18 \mathrm{~ms}$ ) of a 56-year-old patient with aceruloplasminemia (left) and a 65-year-old normal control (right). Marked T2 shortening (hypointensity) due to heavy iron accumulation is apparent in the aceruloplasminemia basal ganglia and thalamus, although TE is low. As seen in the control image, for echo times this short, iron-dependent contrast is not normally evident. Courtesy of Drs. John Schenck and Earl Zimmerman.

Patients with neurodegeneration with brain iron accumulation typically develop retinopathy, dystonia, speech disturbances, and psychiatric manifestations. Iron stains have shown pallidal and nigral iron accumulation. ${ }^{127}$ The T2-weighted brain MRI typically shows an "eye of the tiger" sign, which is a ring of marked hypointensity surrounding a core of hyperintensity involving the bilateral globus pallidus. This hypointense ring has been correlated histologically with iron deposition. Pantothenate kinase 2 has been identified as defective in most cases of neurodegeneration with brain iron accumulation. ${ }^{128,129}$ Excessive iron deposition is believed to occur after pantothenate kinase 2 deficiency leads to accumulation of cysteine containing neurotoxins, which leads to cell damage.

Individuals with aceruloplasminemia show pathological iron accumulation in the brain, retina, and pancreas due to a gene mutation that produces an abnormal ceruloplasmin protein lacking ferroxidase activity. ${ }^{130}$ The disease typically causes extrapyramidal symptoms, ataxia, and retinal degeneration. The MRI shows widespread parenchymal gray matter iron deposits in areas such as the basal ganglia, thalamus, and cerebral cortex (FIG. 4). ${ }^{131,132}$ An absence of functioning ceruloplasmin may lead to an increase in cellular iron deposition due to an inability to remove iron from brain tissue. In a transgenic mouse model, Harris et al. ${ }^{133}$ demonstrated that mice with a mutated ceruloplasmin gene were unable to remove iron from reticuloendothelial cells and hepatocytes. Presumably, ceruloplasmin works to determine the rate of iron efflux in the CNS as well. Thus, a mutated ceruloplasmin gene is likely responsible for the brain iron accumulation seen on MRI in patients with aceruloplasminemia. In addition, ceruloplasmin is thought to have ferroxidase activity that helps shield tissue from free iron $\mathrm{Fe}^{2+}$-induced oxidative damage. This can produce potentially toxic hydrogen peroxidase rather than 
the oxygen and water that would be generated by a normal ceruloplasmin protein. ${ }^{134}$ There is a case report of a patient with aceruloplasminemia exhibiting decreased brain iron, retarded disease progression, and attenuated lipid peroxidation after 10 months of treatment with DES. ${ }^{135}$ Another case report found no effect from DES treatment in a patient heterozygous for the aceruloplasminemia gene. ${ }^{136}$ Recently, zinc sulfate, a compound with known antioxidant activity, has been tested with success in a single heterozygote patient with aceruloplasminemia. ${ }^{137}$

Superficial siderosis can cause hearing loss, ataxia, and myelopathy as a result of chronic slow or repeated bleeding into the subarachnoid space. ${ }^{138}$ Typically a rust brown discoloration of the eighth cranial nerve and cerebellum can be seen on gross examination, which is primarily due to hemosiderin deposition. Postmortem iron staining reveals deposition of hemosiderin in the leptomeninges and subpial tissue. This manifests as T2 hypointensity of the meninges, which is especially evident in the brainstem and spinal cord. ${ }^{138}$ Although poorly understood, there is reason to believe that subpial hemosiderin deposition causes parenchymal damage in the brain and spinal cord. ${ }^{139}$

Chronic toluene abusers can develop a chronic progressive neurological illness characterized by dementia, ataxia, tremor, and nystagmus. Postmortem examination has revealed brain iron deposits in the cerebral gray matter. ${ }^{140}$ The T2-weighted brain MRI typically shows symmetric hypointensity in the thalamus and basal ganglia. ${ }^{141}$ Hypointensity in the motor and visual cortices has been reported as well. ${ }^{141}$ Currently it is unclear whether chronic toluene abuse promotes direct iron toxicity. Rather it remains possible that toluene abuse can lead to demyelination and axonal damage. This in turn can cause secondary iron accumulation from disruption of axonal iron transport.

Hemochromatosis is a disease of iron overload, which typically has no neurological sequelae. There are, however, case reports of patients with either extrapyramidal or cognitive dysfunction. ${ }^{142}$ Berg et al ${ }^{143}$ performed CT and MRI in 14 patients with hereditary hemochromatosis and found signal changes in the basal ganglia, even though all patients remained neurologically asymptomatic. The T2 hypointensity in the basal ganglia of patients with hemochromatosis represents excessive iron deposition. ${ }^{142}$ Individuals with multi-system atrophy, ${ }^{144}$ striatonigral degeneration, ${ }^{145}$ and other Parkinson's plus syndromes $^{146}$ typically show gray matter $\mathrm{T} 2$ hypointensity that has been correlated with iron deposition.

Iron may contribute to the pathogenesis of hypoxic/ ischemic brain injury. Children undergoing MRI after global anoxia show an increased iron deposition in the basal ganglia, thalamus, periventricular, and subcortical white matter. ${ }^{147}$ An absence of proper brain oxygenation leads to local increases in lactic acid, which in turn decrease the ability of transferrin to bind iron. An ischemic environment can also cause the release of ferritinbound iron in a potentially toxic form. A few iron-chelating agents have shown an ability to attenuate infarct size and lead to improved neurological outcome in animal models of stroke. ${ }^{148-150}$ DES lessened brain injury, and mortality in a rat model of global cerebral anoxia. ${ }^{151}$ Methyl tirilazad, a compound thought to inhibit irondependent lipid peroxidation, was administered to patients within 6 hours of initial stroke onset. Functional outcome at 3 months was not significantly different when compared to placebo. ${ }^{152,153}$

Iron may mediate tissue damage in traumatic brain injury (TBI) as well. There are multiple potential effectors of oxidative damage in TBI, at least two of which may be iron related. Oxidative damage driven by iron may occur through anoxic free iron release (as previously described) or through degradation products of heme that may accumulate after TBI. ${ }^{154}$ Studies of DES in TBI animal models have shown a treatment effect. ${ }^{155,156}$ In a randomized, controlled trial, adults with moderate to severe TBI treated with tirilazad mesylate failed to show any benefit when compared with placebo. ${ }^{157}$

\section{IRON-RELATED NEUROTHERAPEUTICS}

Chelators seek to bind iron so that the iron is not free to cause neuronal damage. Numerous mechanisms may explain the neuroprotection provided by DES, but the most common interpretation is that DES acts within the cell to bind iron, forming a hexadentate complex that is nonreactive, thereby inhibiting the ability of the iron to participate in chemical reactions. However, DES may also exert a neuroprotective effect at extracellular sites. Qian and Eaton ${ }^{158}$ proposed that advanced glycation end-products accumulate in diabetics or aging humans, especially in the endothelial internal elastic lamina/basement membranes, and these glycated sites can easily bind transition metals, particularly iron and copper. Thus, when bound in the intima between the endothelium and the vascular smooth muscle, copper and iron are capable of scavenging nitric oxide that is secreted by the endothelial cells to relax the smooth muscle. Therefore, these vessels are in a constant state of vasoconstriction. When chelators are administered, these transition metals are temporarily removed, and nitric oxide can reach the smooth muscle; this results in vasodilation followed by increased blood flow.

Support for this interpretation can be gleaned from the literature in diabetes and cardiology. In a model of diabetic neuropathy in rats, diabetes is induced by injection of streptozotocin and is allowed to develop untreated for 6 weeks. During this time, a significant sciatic nerve 
neuropathy develops, characterized by decreased nutritive blood flow to the nerve and decreased nerve conduction velocity. After 6 weeks, rats are treated with daily subcutaneous DES injections $(8 \mathrm{mg} / \mathrm{kg})$ for 2 weeks. Both blood flow and nerve conduction velocity deficits were significantly ameliorated. ${ }^{159}$

In the same model, a single injection of a high-molecular-weight version of DES (DES coupled to soluble starch) completely reversed the deficit in nutritive blood flow within $24 \mathrm{~h}$ to almost $150 \%$ of normal, and the nerve conduction velocity deficit was normalized 7 days after treatment. Both deficits returned to pretreatment states 28 days after treatment. ${ }^{160}$ Thus, a temporary state of hypoferremia created by infusing the iron chelator DES resulted in increased nutritive blood flow in diabetic rats.

In another study, humans with high-ferritin type 2 diabetes were rendered hypoferremic by phlebotomy, and 18 weeks after the bleeding researchers noted significantly increased vasoactivity of the brachial artery to nitric oxide donors. ${ }^{161}$ Finally, when patients with coronary artery disease and control patients were infused with DES (500 mg during $1 \mathrm{~h}$ ), a significant drop in serum iron concentrations was observed. ${ }^{162}$ In addition, a significant increase in resting forearm blood flow was noted immediately after the start of infusion in both groups, and it persisted for the entire period of infusion.

These studies all report an increase in blood flow or vascular reactivity after a period of hypoferremia. A number of mechanisms can be invoked, but one particular mechanism may be more relevant to the role of iron in tissue damage from neurodegenerative diseases. If iron or copper bound to glycated end-products accumulate in the brain as they do in peripheral tissue, reduced nutritive blood flow could contribute significantly to neurodegeneration with time. This mechanism may explain, in part, the efficacy of long-term DES treatment of $\mathrm{AD},{ }^{24}$ as previously discussed.

Although animal experiments have demonstrated effectiveness in PD, ${ }^{101,103,104} \mathrm{AD},{ }^{83,91}$ and MS, ${ }^{117-120}$ iron chelation therapy in chronic brain disorders in humans has not been studied extensively. A few studies have been successful, ${ }^{24}$ whereas others have not. ${ }^{23,25}$ Because iron-mediated oxidative damage can ultimately lead to neurotoxicity, another approach is to target downstream effects of iron, such as with antioxidants. Such therapies, including coenzyme q10 and vitamin E, may improve cardiac and skeletal muscle function in FA. ${ }^{126}$ An antioxidant similar to coenzyme q10 has also been successful in FA. ${ }^{163}$

In $\mathrm{AD}$, vitamin $\mathrm{E}$ (alpha tocopherol) administered to mice overexpressing amyloid precursor protein had delayed plaque formation and cognitive impairment. ${ }^{164}$ High-dose vitamin $\mathrm{E}$ in $\mathrm{AD}$ patients was unable to prevent a transition from a state of mild cognitive impair- ment to $\mathrm{AD}$, but delayed disease progression in patients with moderately severe AD. ${ }^{165,166}$ Green tea extract $( \pm)$ epigallocatechin-3-gallate N-methyl-4-phenyl-1,2,3,6tetrahydropyridine, a putative antioxidant, has also shown neuroprotection in a mouse model of PD (i.e., preventing loss of substantia nigra dopaminergic neurons). ${ }^{167}$ A comprehensive open label study in humans with PD suggested that treatment with high doses of both vitamins $\mathrm{A}$ and $\mathrm{C}$, putative antioxidants, delayed the need for levodopa or dopamine agonist therapy by 2.5 years. ${ }^{168}$ Many antioxidants have been suggested for use in PD, but have not reached human trials. For a more extensive review on antioxidant therapy in PD, the reader is referred to the recent review by Singh et al. ${ }^{169}$ The EAE models have been attenuated by multiple antioxidants including tirilizad mesylate, ${ }^{148}$ n-acetylcysteine, ${ }^{170}$ catalase,${ }^{171}$ butylated hydroxyanisole,${ }^{172}$ Euk- $8,{ }^{173}$ alpha lipoate, ${ }^{174}$ and a green tea analogue. ${ }^{175}$ Care in applying antioxidant therapy to neurodegenerative disorders should be exercised; a recent meta-analysis identified an increased, all-cause mortality in patients in primary and secondary prevention trials treated with vitamins A and $\mathrm{E}$, and beta carotine. ${ }^{176}$

A metal-protein attenuating compound (MPAC) ideal for the treatment of iron-mediated neurodegenerative disorders would possess a high affinity for iron, be readily absorbed through the gastrointestinal tract, effectively cross the BBB, and carry few side effects. These qualities are found more readily in the MPACs currently being developed. None have proven efficacy in humans, but a few have promising experimental results in animals. Hexadentate MPACs (DES, DP-109), in general, have lower toxicity, but difficulty penetrating the BBB because of their high molecular weight and hydrophilicity. Conversely, bidentate MPACs (defiprone, bathocuproine, feralax, clioquinol, and VK-28) are smaller and more lipophilic, but have greater toxicity. Currently, hexadentate and bidentate iron MPACs are the sole iron chelators that have demonstrated efficacy in either human or animal experiments. The DP-109 is interesting because it is absorbed as a pro-drug that will only begin to chelate with the cleavage of two long-chain esters. The DP-109 has been shown to inhibit plaque formation in an AD mouse model. ${ }^{177}$ Feralax has been shown to disrupt the formation of a protein involved in formation of neurofibrillary tangles. ${ }^{178}$ It remains unclear whether either bathocuproine or feralax will be able to cross the $\mathrm{BBB} .{ }^{179}$ Of the multiple iron chelators that have been recently developed, VK-28 has been designated for further study because of its ability to cross the BBB and provide a potentially more favorable side effect profile. The VK-28, when given intraventricularly to rats in a model of PD, prevented depletion of striatal dopamine. ${ }^{180}$ The M-30, a compound synthesized from VK28 , but with an additional monoamine oxidase moiety, 
has been found to attenuate the dopamine-depleting action of MPTP in mice; it has also been found to increase striatal levels of dopamine, serotonin and norepinephrine, while decreasing their metabolites. ${ }^{181}$ Interestingly, Liu et al. ${ }^{182}$ have synthesized a chelator attached to a nanoparticle that complexes with iron. They demonstrate that this addition is likely to promote BBB absorption. ${ }^{182}$ Thus, clearly the neurotherapeutic pipeline for iron-related neurotherapies is actively growing in depth and breadth.

\section{CONCLUSIONS}

In this review, we have examined MRI techniques, discussed current understandings of iron metabolism, and summarized studies attempting to understand the role of iron in neurotherapeutic development. We have seen that in vivo monitoring of iron by traditional MRI has been supplanted by emerging MRI techniques. A range of MRI techniques will continue to be optimized so that even better sensitivity, specificity, and spatial resolution will be achieved. We have discussed the transport and metabolism of brain iron and where it normally accumulates with aging. We have examined the hypothesis that excessive brain iron can lead to free radical damage, lipid peroxidation, and cellular death. We have explored the potential link between excessive iron and many chronic brain disorders including $\mathrm{AD}, \mathrm{PD}$, and MS. We have reviewed animal and human studies exploring the potential neurotherapeutic role of targeting iron mediated and oxidative damage. We have also discussed interesting new neurotherapeutic developments in the pipeline aimed at mitigating iron-mediated and oxidative-related brain injury. Future research will undoubtedly lead to a better understanding of the role that iron plays in neurodegenerative diseases and help facilitate development of better neurotherapies for patients.

Acknowledgments: This work was supported by research grants to Dr. Bakshi from the National Institutes of Health (NIH-NINDS 1 K23 NS42379-01) and the National Multiple Sclerosis Society (RG3705A1; RG3798A2). We thank Ms. Sophie Tamm for her editorial assistance.

\section{REFERENCES}

1. Gutteridge JM. Iron and oxygen radicals in brain. Ann Neurol 1992;32:S16-S21.

2. Pujol J, Juque C, Vendrell $P$, et al. Biological significance of iron-related magnetic resonance imaging changes in the brain. Arch Neurol 1992;49:711-717.

3. Wills AJ, Sawle GV, Guilbert PR, Curtis AR. Palatal tremor and cognitive decline in neuroferritinopathy. J Neurol Neurosurg Psychiatry 2002;73:91-92.

4. Riederer P, Sofic E, Rausch WD, et al. Transition metals, ferritin, glutathione, and ascorbic acid in parkinsonian brains. J Neurochem 1989;52:515-520.

5. Dexter DT, Wells FR, Agid F, et al. Increased nigral iron content in post-mortem parkinsonian brain. Lancet 1987;341:1219-1220.
6. Berg D, Hochstrasser H. Iron metabolism in Parkinsonian syndromes. Mov Disord 2006;21:1299-1310.

7. Jenner P. Oxidative stress as a cause of Parkinson's disease. Acta Neurol Scand Suppl 1991;136:6-15.

8. Jenner P, Olanow CW. Oxidative stress and the pathogenesis of Parkinson's disease. Neurology 1996;47(suppl 3):S161-S170.

9. Cohen G. Oxidative stress, mitochondrial respiration, and Parkinson's disease. Ann NY Acad Sci 2000;899:112-120.

10. Youdim MB, Ben-Shachar D, Riederer P. Parkinson's disease and increased iron levels in substantia nigra zona compacta. Mov Disord 1993;8:1-12.

11. House MJ, St Pierre TG, Kowdley KV, et al. Correlation of proton transverse relaxation rates (R2) with iron concentrations in postmortem brain tissue from Alzheimer's disease patients. Magn Reson Med 2007;57:172-180.

12. Loeffler DA, Connor JR, Juneau PL, et al. Transferrin and iron in normal, Alzheimer's disease, and Parkinson's disease brain regions. J Neurochem 1995;65:710-716.

13. Connor JR, Snyder BS, Beard JL, Fine RE, Mufson EJ. Regional distribution of iron and iron-regulatory proteins in the brain in aging and Alzheimer's disease. J Neurosci Res 1992;31:327-335.

14. Cornett CR, Markesbery WR, Ehmann WD. Imbalances of trace elements related to oxidative damage in Alzheimer's disease brain. Neurotoxicology 1998;19:339-346.

15. Dedman DJ, Treffry A, Candy JM, et al. Iron and aluminum in relation to brain ferritin in normal individuals and Alzheimer'sdisease and chronic renal-dialysis patients. Biochem J 1992;287: 509-514.

16. Ehmann WD, Markesbery WR, Alauddin M, Hossain TI, Brubaker EH. Brain trace elements in Alzheimer's disease. Neurotoxicology 1986;7:195-206.

17. Honda K, Casadesus G, Petersen RB, et al. Oxidative stress and redox-active iron in Alzheimer's disease. Ann NY Acad Sci 2004;1012:179-182.

18. Drayer B, Burger P, Hurwitz B, et al. Reduced signal intensity on MR Images of thalamus and putamen in multiple sclerosis: increased iron content? AJR Am J Roentgenol 1987;149:357-363.

19. Bakshi R, Benedict RH, Bermel RA, et al. T2 hypointensity in the deep gray matter of patients with multiple sclerosis: a quantitative magnetic resonance imaging study. Arch Neurol 2002;59:62-68.

20. Craelius W, Migdal WM, Lussenhop CP, et al. Iron deposits surrounding multiple sclerosis plaques. Arch Pathol Lab Med 1982;106:397-399.

21. Inglese $\mathrm{M}, \mathrm{Ge} \mathbf{Y}$, Jensen $\mathrm{J}$, et al. Iron accumulation in the deep gray matter of patients with MS measured by magnetic field correlation. Neurology 2005;64(suppl 1):A236.

22. Brass SD, Chen NK, Mulkern RV, Bakshi R. Magnetic resonance imaging of iron deposition in neurological disorders. Top Magn Reson Imaging 2006;17:31-40.

23. Ritchie CW, Bush AI, Mackinnon A, et al. Metal-protein attenuation with iodochlorhydroxyquin (clioquinol) targeting Abeta amyloid deposition and toxicity in Alzheimer disease: a pilot phase 2 clinical trial. Arch Neurol 2003;60:1685-1691.

24. Crapper McLachlan DR, Dalton AJ, Kruck TP, et al. Intramuscular desferrioxamine in patients with Alzheimer's disease. Lancet 1991;337:1304-1308.

25. Lynch SG, Fonseca T, Levine SM, et al. A multiple course trial of desferrioxamine in chronic progressive multiple sclerosis. Cell Mol Biol 2000;46:865-869.

26. Schenck JF. Magnetic resonance imaging of brain iron. J Neurol Sci 2003;207:99-102.

27. Haacke EM, Cheng NY, House MJ, et al. Imaging iron stores in the brain using magnetic resonance imaging. Magn Reson Imaging 2005;23:1-25.

28. Vymazal J, Brooks RA, Baumgarner C, et al. The relation between brain iron and NMR relaxation times: an in vitro study. Magn Reson Med 1996;35:56-61.

29. Chen JC, Hardy PA, Clauberg M, et al. T2 values in the human brain: comparison with quantitative assays of iron and ferritin. Radiology 1989;173:521-526.

30. Bartzokis G, Sultzer D, Mintz J, et al. In vivo evaluation of brain iron in Alzheimer's disease and normal subjects using MRI. Biol Psych 1994;35:480-487. 
31. Bartzokis G, Cummings JL, Markham CH, et al. MRI evaluation of brain iron in earlier- and later-onset Parkinson's disease and normal subjects. Magn Reson Imaging 1999;17:213-222.

32. Bartzokis G, Tishler TA. MRI evaluation of basal ganglia ferritin iron and neurotoxicity in Alzheimer's and Huntington's disease. Cell Mol Biol 2000;46:821-833.

33. Gelman N, Gorell JM, Barker PB, et al. MR imaging of human brain at 3.0 T: preliminary report on transverse relaxation rates and relation to estimated iron content. Radiology 1999;210:759767.

34. Metafratzi Z, Argyropoulou MI, Kiortsis DN, et al. T(2) relaxation rate of basal ganglia and cortex in patients with betathalassaemia major. Br J Radiol 2001;74:407-410.

35. Schenck JF. Imaging of brain iron by magnetic resonance: T2 relaxation at different field strengths. J Neurol Sci 1995; 134(suppl):10-18.

36. Vymazal J, Righini A, Brooks RA, et al. $\mathrm{T} 1$ and $\mathrm{T} 2$ in the brain of healthy subjects, patients with Parkinson disease, and patients with multiple system atrophy: relation to iron content. Radiology 1999;211:489-495.

37. Hardy PA, Gash D, Yokel R, Andersen A, Ai Y, Zhang Z. Correlation of R2 with total iron concentration in the brains of rhesus monkeys. J Magn Reson Imaging 2005;21:118-127.

38. Graham JM, Paley MN, Grunewald RA, Hoggard N, Griffiths PD. Brain iron deposition in Parkinson's disease imaged using the PRIME magnetic resonance sequence. Brain 2000;123:2423-2431.

39. Whittall KP, MacKay AL, Graeb DA, et al. In vivo measurement of T2 distributions and water contents in normal human brain. Magn Reson Med 1997;37:34-43.

40. Ordidge RJ, Gorell JM, Deniau JC, Knight RA, Helpern JA. Assessment of relative brain iron concentrations using T2weighted and T2*-weighted MRI at 3 Tesla. Magn Reson Med 1994;32:335-341.

41. Gorell JM, Ordidge RJ, Brown GG, et al. Increased iron-related MRI contrast in the substantia nigra in Parkinson's disease. Neurology 1995;45:1138-1143.

42. Antonini A, Leenders KL, Meier D, et al. T2 relaxation time in patients with Parkinson disease. Neurology 1993;43:697-700.

43. Bartzokis G, Aravagiri M, Oldendorf WH, Mintz J, Marder SR. Field dependent transverse relaxation rate increase may be a specific measure of tissue iron stores. Magn Reson Med 1993; 29:459-464.

44. Reichenbach JR, Venkatesan R, Yablonskiy DA, et al. Theory and application of static field inhomogeneity effects in gradientecho imaging. J Magn Reson Imaging 1997;7:266-279.

45. Ma J, Wehrli F. Method for image-based measurement of the reversible and irreversible contribution to the transverse-relaxation rate. J Magn Reson Imaging 1996;111:61-69.

46. Song R, Song HK. Echo-spacing optimization for the simultaneous measurement of reversible (R2') and irreversible (R2) transverse relaxation rates. Magn Reson Imaging 2007;25:63-68.

47. Hikita T, Abea K, Sakodaa S, et al. Determination of transverse relaxation rate for estimating iron deposits in central nervous system. Neurosci Res 2005;51:67-71.

48. Yablonskiy D, Haacke M. An MRI method for measuring T2 in the presence of static and RF magnetic field inhomogeneities. Magn Reson Med 1997;37:872-876.

49. Wheaton AJ, Borthakur A, Corbo MT, et al. T2rho-weighted contrast in MR images of the human brain. Magn Reson Med 2004;52:1223-1227.

50. Michaeli S, Oz G, Sorce DJ, et al. Assessment of brain iron and neuronal integrity in patients with Parkinson's disease using novel MRI contrasts. Mov Disord 2007;22:334-340.

51. Jensen JH, Chandra R, Ramani A, et al. Magnetic field correlation imaging. Magn Reson Med 2006;55:1350-1361.

52. Ponka P. Heredity causes of disturbed iron homeostasis in the central nervous system. Ann NY Acad Sci 2004;1012:267-281.

53. Connor JR, Menzies SL. Relationship of iron to oligodendrocytes and myelination. Glia 1996;17:83-93.

54. Floris G, Meddad R, Padiglia A, Musci G. The physiopathological significance of ceruloplasmin. Biochem Pharmacol 2000;60: 1735-1741.
55. Pantopoulos K. Iron metabolism and the IRE/IRP regulator system: an update. Ann NY Acad Sci 2004;1012-1013.

56. Ke Y, Qian ZM. Iron misregulation in the brain: a primary cause of neurodegenerative disorders. Lancet Neurol 2003;2:246-253.

57. Connor JR, Boeshore SA, Benkovic SA, Menzies SL. Isoforms of ferritin have a specific cellular distribution in the brain. J Neurosci Res 1994;37:461-465.

58. Levi S, Yewdall SJ, Harrison PM, et al. Evidence that H- and L-chains have co-operative roles in the iron-uptake mechanism of human ferritin. J Biochem 1992;288:591-596.

59. Zecca L, Stroppolo A, Gatti A, et al. The role of iron and copper molecules in the neuronal vulnerability of locus coeruleus and substantia nigra during aging. Proc Natl Acad Sci U S A 2004; 101:9843-9848.

60. Zecca L, Zucca FA, Albertini A, Rizzio E, Fariello RG. A proposed dual role of neuromelanin in the pathogenesis of Parkinson's disease. Neurology 2006;67(suppl 2):S8-S11.

61. Moos T, Morgan EH. Evidence for low molecular weight, nontransferrin-bound iron in rat brain and cerebrospinal fluid. J Neurosci Res 1998;54:486-494.

62. Curtis AR, Fey C, Morris CM, et al. Mutation in the gene encoding ferritin light polypeptide causes dominant adult-onset basal ganglia disease. Nat Genet 2001;28:350-354.

63. Schipper HM. Heme oxygemase-1: transducer of pathological brain iron sequestration under oxidative stress. Ann NY Acad Sci 2004;1012:84-93.

64. Fenton HJH. Oxidation of tartaric acid in presence of iron J Chem Soc 1894;65:899-903.

65. Liddell JR, Hoepken HH, Crack PJ, Robinson SR, Dringen R. Glutathione peroxidase 1 and glutathione are required to protect mouse astrocytes from iron-mediated hydrogen peroxide toxicity. J Neurosci Res 2006;84:578-586.

66. Aguirre P, Mena N, Tapia V, et al. Antioxidant responses of cortex neurons to iron loading. Biol Res 2006;39:103-104.

67. Crichton RR, Wilmet S, Legssyer R, Ward RJ. Molecular and cellular mechanisms of iron homeostasis and toxicity in mammalian cells. J Inorg Biochem 2002;91:9-18.

68. Van der Worp HB, Thomas CE, Kappelle LJ, et al. Inhibition of iron-dependent and ischemia-induced brain damage by the alphatocopherol analogue MDL74,722. Exp Neurol 1999;155:103108.

69. de Jesus Ferreira MC, Crouzin N, Barbanel G, et al. A transient treatment of hippocampal neurons with alpha-tocopherol induces a long-lasting protection against oxidative damage via a genomic action. Free Radic Biol Med 2005;39:1009-1020.

70. Moos T. Brain iron homeostasis. Dan Med Bull 2002;49:279301.

71. Connor JR, Menziew SL, St. Martin SM, Mufson EJ. Cellular distribution of transferrin, ferritin and iron in normal and aged human brains. J Neurosci Res 1990;27:595-611.

72. Zucca FA, Bellei C, Giannelli S, et al. Neuromelanin and iron in human locus coeruleus and substantia nigra during aging: consequences for neuronal vulnerability. J Neural Transm 2006;113: $757-767$.

73. Zecca L, Youdim MBH, Riederer P, Conner JR, Crichton RR. Iron, brain ageing and neurodegenerative disorders. Nat Rev Neurosci 2004;5:863-873.

74. Rouault TA. Iron on the brain. Nat Genet 2001;28:299-300.

75. Drayer B, Burger P, Darwin R, et al. MRI of brain iron. AJR Am J Roentgenol 1986;147:103-110.

76. Hallgren B, Sourander P. The effect of age on the non-haemin iron in the human brain. J Neurochem 1958;3:41-51.

77. Thomas LO, Boyko OB, Anthony DC, Burger PC. MR detection of brain iron. AJNR Am J Neuroradiol 1993;14:1043-1048.

78. Milton WH, Atlas SW, Lexa FJ, Mozley PD, Gur RE. Deep gray matter hypointensity patterns with aging in healthy adults: MR imaging at 1.5T. Radiology 1991;181:715-719.

79. Bartzokis G, Beckson M, Hance DB, et al. MR evaluation of age-related increase of brain iron in young adult and older normal males. Magn Reson Imaging 1997;15:29-35.

80. Bartzokis G, Tishler TA, Lu PH, et al. Brain ferritin iron may influence age- and gender-related risks of neurodegeneration. Neurobiol Aging 2007;28:414-423. 
81. Cass WA, Grondin R, Andersen AH, et al. Iron accumulation in the striatum predicts aging-related decline in motor function in rhesus monkeys. Neurobiol Aging 2007;28:258-271.

82. Richardson DR. Novel chelators for central nervous system disorders that involve alterations in the metabolism of iron and other metal ions. Ann NY Acad Sci 2004;1012:326-341.

83. Rottkamp CA, Raina AK, Zhu X, et al. Redox-active iron mediates amyloid- $\beta$ toxicity. Free Radical Biol Med 2001;30:447450.

84. Mantyh PW, Ghilardi JR, Rogers S, et al. Aluminum, iron, and zinc ions promote aggregation of physiological concentrations of $\beta$-amyloid peptide. J Neurochem 1993;61:1171-1174.

85. Bishop GM, Robinson SR. $\beta$-Amyloid helps to protect neurons from oxidative stress. Neurobiol Aging 2000;21(suppl 1):226.

86. Van Landeghem G, Sikstrom C, Beckman L, Adolfsson R, Beckman R. Transferrin C2, metal binding and Alzheimer's disease. Neuroreport 1998;9:177-179.

87. Pulliam JF, Jennings CD, Kryscio RJ, et al. Association of HFE mutations with neurodegeneration and oxidative stress in Alzheimer's disease and correlation with APOE. Am J Med Genet B Neuropsychiatr Genet 2003;119:48-53.

88. Bartzokis G, Sultzer D, Cummings J, et al. In vivo evaluation of brain iron in Alzheimer disease using magnetic resonance imaging. Arch Gen Psychiatry 2000;57:47-53.

89. Bartzokis G, Tishler TA, Shin I, Lu PH, Cummings JL. Brain ferritin iron as a risk factor for age at onset in neurodegenerative diseases. Ann NY Acad Sci 2004;1012:224-236.

90. House MJ, St Pierre TG, Foster JK, et al. Quantitative MR imaging R2 relaxometry in elderly participants reporting memory loss. AJNR Am J Neuroradiol 2006;27:430-439.

91. Cherny RA, Atwood CS, Xilinas ME, et al. Treatment with a copper-zinc chelator markedly and rapidly inhibits beta-amyloid accumulation in Alzheimer's disease transgenic mice. Neuron 2001;30:665-676.

92. Uitti RJ, Rajput AH, Rozdilsky B, et al. Regional metal concentrations in Parkinson's disease, other chronic neurological diseases, and control brains. Can J Neurol Sci 1989;16:310-314.

93. Galazka-Friedman J, Bauminger ER, Friedman A, et al. Iron in parkinsonian and control substantia nigra: a Mossbauer spectroscopy study. Mov Disord 1996;11:8-16.

94. Youdim MB, Ben Shachar D, Riedere P. Is Parkinson's disease a progressive siderosis of substantia nigra resulting in iron and melanin induced neurodegeneration. Acta Neurol Scand 1989(suppl);126:47-54.

95. Levenson CW. Iron and Parkinson's disease: Chelators to the rescue? Nutr Rev 2003;61:311-313.

96. Andersen JK. Do alterations in glutathione and iron levels contribute to pathology associated with Parkinson's disease? Novartis Found Symp 2001;235:11-20.

97. Dexter DT, Carayon A, Vidailhet M, et al. Decreased ferritin levels in brain in Parkinson's disease. J Neurochem 1990;55:1620.

98. Zecca L, Berg D, Arzberger T, et al. In vivo detection of iron and neuromelanin by transcranial sonography: a new approach for early detection of substantia nigra damage. Mov Disord 2005;20: $1278-1285$.

99. Atasoy HT, Nuyan O, Tunc T, et al. T2-weighted MRI in Parkinson's disease; substantia nigra pars compacta hypointensity correlates with the clinical scores. Neurology India 2004;52:332337.

100. Kosta P, Argyropoulou MI, Markoula S, et al. MRI evaluation of the basal ganglia size and iron content in patients with Parkinson's disease. J Neurol 2006;253:26-32.

101. Gerlach M, Double KL, Youdim MB, Riederer P. Potential sources of increased iron in the substantia nigra of parkinsonian patients. J Neural Transm Suppl 2006;70:133-42.

102. Shoham S, Youdim MB. Nutritional iron deprivation attenuates kainate-induced neurotoxicity in rats: implications for involvement of iron in neurodegeneration. Ann NY Acad Sci 2004;1012: 94-114.

103. Ben-Shachar D, Eshel G, Finberg JP, Youdim MB. The iron chelator desferrioxamine (desferal) retards 6-hydroxydopamine- induced degeneration of nigrostriatal dopamine neurons. J Neurochem 1991;56:1441-1444.

104. Lan J, Jiang DH. Desferrioxamine and vitamin E protect against iron and MPTP-induced neurodegeneration in mice. $J$ Neural Transm 1997;104:469-481.

105. Kaur D, Yantiri F, Rajagopalan S, et al. Genetic or pharmacological iron chelation prevents MPTP-induced neurotoxicity in vivo: a novel therapy for Parkinson's disease. Neuron 2003;27: 899-909.

106. Bakshi R, Shaikh ZA, Janardhan V. MRI T2 shortening ("black T2") in multiple sclerosis: frequency, location, and clinical correlation. Neuroreport 2000;11:15-21.

107. Tjoa CW, Benedict RH, Weinstock-Guttman B, Fabiano AJ, Bakshi R. MRI T2 hypointensity of the dentate nucleus is related to ambulatory impairment in multiple sclerosis. J Neurol Sci 2005; 234:17-24.

108. Neema M, Stankiewicz J, Arora A, et al. T1- and T2-based MRI measures of diffuse gray matter and white matter damage in patients with multiple sclerosis. J Neuroimaging 2007;17(suppl 1):16-21.

109. LeVine SM. Iron deposits in multiple sclerosis and Alzheimer's disease brains. Brain Res 1997;760:298-303.

110. Mehindate K, Sahlas DJ, Frankel D, et al. Proinflammatory cytokines promote glial heme oxygenase- 1 expression and mitochondrial iron deposition: implications for multiple sclerosis. J Neurochem 2001;77:1386-1395.

111. Chakrabarty MR, Emerson R, Levine SM. Heme oxygenase-1 in SJL mice with experimental allergic encephalomyelitis. Multiple Sclerosis 2003;9:372-381.

112. Forge JK, Pedchenko TV, LeVine SM. Iron deposits in the central nervous system of SJL mice with experimental allergic encephalomyelitis. Life Sci 1998;63:2271-2284.

113. Bakshi R, Shaikh ZA, Janardhan V. MRI T2 shortening ("black T2") in multiple sclerosis: frequency, location, and clinical correlation. Neuroreport 2000;11:15-21.

114. Brass SD, Benedict RH, Weinstock-Guttman B, Munschauer F, Bakshi R. Cognitive impairment is associated with subcortical magnetic resonance imaging grey matter T2 hypointensity in multiple sclerosis. Mult Scler 2006;12:437-444.

115. Bermel RA, Puli SR, Rudick RA, et al. Prediction of longitudinal brain atrophy in multiple sclerosis by gray matter magnetic resonance imaging T2 hypointensity. Arch Neurol 2005;62:13711376.

116. Zhang Y, Zabad RK, Wei X, Metz LM, Hill MD, Mitchell JR. Deep gray matter "black T2" on 3 tesla magnetic resonance image correlates with disability in multiple sclerosis. Mult Scler April 27, 2007 [E-pub ahead of print].

117. Bowern N, Ramshaw I, Clark I, Doherty P. Inhibition of autoimmune neuropathological process by treatment with an ironchelating agent. J Exp Med 1984;160:1532-1543.

118. Willenborg DO, Bowern NA, Danta G, Doherty PC. Inhibition of allergic encephalomyelitis by the iron chelating agent desferrioxamine: differential effect depending on type of sensitizing encephalitogen. J Neuroimmunol 1988;17:127-135.

119. Pedchenko TV, LeVine SM. Desferrioxamine suppresses experimental allergic encephalomyelitis induced by MBP in SJL mice. J Neuroimmunol 1998;84:188-197.

120. Weilbach FX, Chan A, Toyka KV, et al. The cardioprotector dexrazoxane augments therapeutic efficacy of mitoxantrone in experimental autoimmune encephalomyelitis. Clin Exp Immunol 2004;135:49-55.

121. Pai VB, Nahata MC. Cardiotoxicity of chemotherapeutic agents: incidence, treatment and prevention. Drug Saf 2000;4:263-302.

122. Mancuso M, Davidzon G, Kurlan RM, et al. Hereditary ferritinopathy: a novel mutation, its cellular pathology, and pathogenetic insights. J Neuropathol Exp Neurol 2005;64:280-294.

123. Chinnery PF, Crompton DE, Birchall D, et al. Clinical features and natural history of neuroferritinopathy caused by the FTL1 460InsA mutation. Brain 2007;130:110-119.

124. Duby G, Foury F, Ramazzotti A, Herrmann J, Lutz T. A nonessential function for yeast frataxin in iron-sulfur cluster assembly. Hum Mol Genet 2002;11:2635-2643. 
125. Waldvogel D, van Gelderen P, Hallet M. Increased iron in the dentate nucleus of patients with Friedrich's ataxia. Ann Neurol 1999;46:123-125.

126. Hart PE, Lodi R, Rajagopalan B, et al. Antioxidant treatment of patients with Friedreich ataxia: four-year follow-up. Arch Neurol 2005;62:621-626.

127. Hayflick SJ, Hartman M, Coryell J, Gitschier J, Rowley H. Brain MRI in neurodegeneration with brain iron accumulation with and without PANK2 mutations. AJNR Am J Neuroradiol 2006;27: $1230-1233$.

128. Zhou B, Westaway SK, Levinson B, et al. A novel pantothenate kinase gene (PANK2) is defective in Hallervorden-Spatz syndrome. Nat Genet 2001;28:345-349.

129. Hayflick SJ. Unraveling the Hallervorden-Spatz syndrome: pantothenate kinase-associated neurodegeneration is the name. Curr Opin Pediatr 2003;15:572-577.

130. Xu X, Pin S, Gathinji M, Fuchs R, Harris ZL. Aceruloplasminemia: an inherited neurodegenerative disease with impairment of iron homeostasis. Ann N Y Acad Sci 2004;1012:299-305.

131. Kawanami T, Kato T, Daimon M, et al. Hereditary caeruloplasmin deficiency: clinicopathological study of a patient. J Neurol Neurosurg Psychiatry 1996;61:506-509.

132. Grisoli M, Piperno A, Chiapparini L, Mariani R, Savoiardo M. MR imaging of cerebral cortical involvement in aceruloplasminemia. AJNR Am J Neuroradiol 2005;26:657-61.

133. Harris ZL, Durley AP, Man TK, Gitlin JD. Targeted gene disruption reveals an essential role for ceruloplasmin in cellular iron efflux. Proc Natl Acad Sci USA 1999;96:10812-10817.

134. Vassiliev V, Harris ZL, Zatta P. Ceruloplasmin in neurodegenerative diseases. Brain Res Brain Res Rev 2005;49:633-640.

135. Miyajima H, Takahaski Y, Kamata T, et al. Use of desferrioxamine in the treatment of aceruloplasminemia. Ann Neurol 1997; 41:404-407.

136. Loreal O, Turlin B, Pigeon C, et al. Aceruloplasminemia: new clinical, pathophysiological and therapeutic insights. J Hepatol 2002;36:851-856.

137. Kuhn J, Bewermeyer H, Miyajima H, et al. Treatment of symptomatic heterozygous aceruloplasminemia with oral zinc sulphate. Brain Dev 2007;7:450-453.

138. Levy M, Turtzo C, Llinas RH. Superficial siderosis: a case report and review of the literature. Nat Clin Pract Neurol 2007;3:54-58.

139. Koeppen AH, Dickson AC, Chu RC, Thach RE. The pathogenesis of superficial siderosis of the central nervous system. Ann Neurol 1993;34:646-653.

140. Unger E, Alexander A, Fritz T, Rosenberg N, Dreisbach J. Toluene abuse: physical basis for hypointensity of the basal ganglia on T2-weighted images. Radiology 1994;193:473-476.

141. Kamran S, Bakshi R. MRI in chronic toluene abuse: low signal in the cerebral cortex on T2-weighted images. Neuroradiology 1998;40:519-521.

142. Nielsen JE, Neerup Jensen L, Krabbe K. Hereditary haemochromatosis: a case of iron accumulation in the basal ganglia associated with a parkinsonian syndrome. J Neurol Neurosurg Psychiatry 1995;59:318-321.

143. Berg D, Hoggenmuller U, Hofmann E, et al. The basal ganglia in haemochromatosis. Neuroradiology 2000;42:9-13.

144. Savoiardo M, Differential diagnosis of Parkinson's disease and atypical parkinsonian disorder by magnetic resonance imaging. Neurol Sci 2003;24(suppl 1):S35-S37.

145. Block S, Bakshi R. FLAIR MRI of striatonigral degeneration. Neurology 2001;56:1200.

146. Hauser RA, Murtaugh FR, Akhter K, et al. Magnetic resonance imaging of corticobasal degeneration. J Neuroimaging 1996;6: 222-226.

147. Dietrich RB, Bradley WG Jr. Iron accumulation in the basal ganglia following severe ischemic-anoxic insults in children. Radiology 1988;168:203-206.

148. Hall ED. Novel inhibitors of iron-dependent lipid peroxidation for neurodegenerative disorders. Ann Neurol 1992;32:S137S142.

149. Feng Y, LeBlanc M, LeBlanc E, et al. Desmethyl tirilazad improves neurologic function after hypoxic-ischemic brain injury in piglets. Crit Care Med 2000;28:1431-1438.
150. Soloniuk D, Perkins E, Wilson J. Use of allopurinol and deferoxamine in cellular protection during ischemia. Surg Neurol 1992;38:110-113.

151. Rosenthal E, Chanderbhan R, Marshall G, Fiskum G. Prevention of post-ischemic brain lipid conjugated diene production and neurological injury by hydroxyethyl starch-conjugated deferoxamine. Free Radic Biol Med 1992;12:29-33.

152. RANTTAS Investigators. A randomized trial of tirilazad mesylate in patients with acute stroke (RANTTAS). Stroke 1996;27: $1453-1458$

153. Haley EC Jr. High-dose tirilazad for acute stroke (RANTTAS II). Stroke 1998;29:1256-1257.

154. Balla G, Vercellotti GM, Muller-Eberhard U, Eaton J, Jacob HS. Exposure of endothelial cells to free heme potentiates damage mediated by granulocytes and toxic oxygen species. Lab Invest 1991;64:648-655.

155. Long DA, Ghosh K, Moore AN, Dixon CE, Dash PK. Deferoxamine improves spatial memory performance following experimental brain injury in rats. Brain Res 1996;717:109-117.

156. Panter SS, Baughler JM, Hall ED. Dextran-coupled deferoxamine improves outcome in a murine model of head injury. J Neurotrauma 1992;9:47-53.

157. Marshall LF, Maas AI, Marshall SB, et al. A multicenter trial on the efficacy of using tirilazad mesylate in cases of head injury. J Neurosurg 1998;89:519-525.

158. Qian M, Eaton JW. Glycochelates and the etiology of diabetic peripheral neuropathy. Free Radic Biol Med 2000;28:652-656.

159. Cameron NE, Cotter MA. Neurovascular dysfunction in diabetic rats. Potential contribution of autoxidation and free radicals examined using transition metal chelating agents. J Clin Invest 1995;96:1159-1163.

160. Cameron NE, Cotter MA. Effects of an extracellular metal chelator on neurovascular function in diabetic rats. Diabetologia 2001;44:621-628.

161. Fernandez-Real JM, Penarroja G, Castro A, Garcia-Bragado F, Lopez-Bermejo A, Ricart W. Blood letting in high-ferritin type 2 diabetes: effects on vascular reactivity. Diabetes Care 2002;25: 2249-2255.

162. Duffy SJ, Biegelsen ES, Holbrook M, et al. Iron chelation improves endothelial function in patients with coronary artery disease. Circulation 2001;103:2799-2804.

163. Buyse G, Mertens L, Di Salvo G, et al. Idebenone treatment in Friedreich's ataxia. Neurology 2003;60:1679-1681.

164. Pratico D, Uryu K, Leight S, Trojanoswki JQ, Lee VM. Increased lipid peroxidation precedes amyloid plaque formation in an animal model of Alzheimer amyloidosis. J Neurosci 2001;21:41834187.

165. Petersen RC, Thomas RG, Grundman M, et al. Vitamin E and donepezil for the treatment of mild cognitive impairment. N Engl J Med 2005;352:2379-2388.

166. Sano M, Ernesto C, Thomas RG, et al. A controlled trial of selegiline, alpha-tocopherol, or both as treatment for Alzheimer's disease. N Engl J Med 1997;336:1216-1222.

167. Levites Y, Weinreb O, Maor G, Youdim MB, Mandel S. Green tea polyphenol (-)-epigallocatechin-3-gallate prevents N-methyl4-phenyl-1,2,3,6-tetrahydropyridine-induced dopaminergic neurodegeneration. J Neurochem 2001;78:1073-1082.

168. Fahn S, Cohen G. The oxidant stress hypothesis in idiopathic Parkinson's: evidence supporting it. Ann Neurol 1992;32:799803.

169. Singh N, Pillay V, Choonara YE. Advances in the treatment of Parkinson's disease. Prog Neurobiol 2007;81:29-44.

170. Lehmann D, Karussis D, Misrachi-Koll R, et al. Oral administration of the oxidant scavenger N-acetyl-L-cysteine inhibits acute experimental autoimmune encephalomyelitis. J Neuroimmunol 1994;50:35-42.

171. Ruuls SR, Bauer J, Sontrop K, et al. Reactive oxygen species are involved in the pathogenesis of experimental allergic encephalomyelitis in Lewis rats. J Neuroimmunol 1995;56:207-217.

172. Hansen LA, Willenborg DO, Cowden WB. Suppression of hyperacute and passively transferred experimental autoimmune encephalomyelitis by the antioxidant, butylated hydroxyanisole. J Neuroimmunol 1995;62:69-77. 
173. Malfroy B, Doctrow SR, Orr PL, Tocco G, Fedoseyeva EV, Benichou G. Prevention and suppression of autoimmune encephalomyelitis by EUK-8, a synthetic catalytic scavenger of oxygenreactive metabolites. Cell Immunol 1997;177:62-68.

174. Marracci GH, Jones RE, McKeon GP, et al. Alpha lipoic acid inhibits $\mathrm{T}$ cell migration into the spinal cord and suppresses and treats experimental autoimmune encephalomyelitis. J Neuroimmunol 2002;13:104-114.

175. Aktas O, Prozorovski T, Smorodchenko A, et al. Green tea epigallocatechin-3-gallate mediates T cellular NF-kappa B inhibition and exerts neuroprotection in autoimmune encephalomyelitis. J Immunol 2004;173:5794-5800.

176. Bjelakovic G, Nikolova D, Gluud LL, Simonetti RG, Gluud C. Mortality in randomized trials of antioxidant supplements for primary and secondary prevention: systematic review and metaanalysis. JAMA 2007;297:842-857.

177. Lee JY, Friedman JE, Angel I, Kozak A, Koh JY. The lipophilic metal chelator DP-109 reduces amyloid pathology in brains of human b-amyloid precursor protein transgenic mice. Neurobiol Aging 2004;25:1315-1321

178. Shin RW, Kruck TP, Murayama H, Kitamoto T. A novel trivalent cation chelator Feralex dissociates binding of aluminum and iron associated with hyperphosphorylated tau of Alzheimer's disease. Brain Res 2003;961:139-146.

179. Gaeta A, Hider RC. The crucial role of metal ions in neurodegeneration: the basis for a promising therapeutic strategy. $\mathrm{Br} \mathrm{J}$ Pharmacol 2005;146:1041-1059.

180. Ben-Shachar D, Kahana N, Kampel V, Warshawsky A, Youdim MB. Neuroprotection by a novel brain permeable iron chelator, VK-28, against 6-hydroxydopamine lesion in rats. Neuropharmacology 2004;46:254-263.

181. Gal S, Zheng H, Fridkin M, Youdim MB. Novel multifunctional neuroprotective iron chelator-monoamine oxidase inhibitor drugs for neurodegenerative diseases. In vivo selective brain monoamine oxidase inhibition and prevention of MPTPinduced striatal dopamine depletion. J Neurochem 2005;95: $79-88$.

182. Liu G, Men P, Harris PL, et al. Nanoparticle iron chelators: a new therapeutic approach in Alzheimer disease and other neurologic disorders associated with trace metal imbalance. Neurosci Lett 2006;406:189-193. 